\title{
What is prehistory
}

\section{Marcel Otte*}

Department of Prehistory, University of Liege, Belgium

Submission: August 24, 2019; Published: September 23, 2019

*Corresponding author: Marcel Otte, Department of Prehistory, University of Liege, Belgium

\begin{abstract}
Prehistory works like a mirror of our self; it defies trajectories that explain and justify us. Its fascination power is also taken from textural, plastic and the spirit that comes out of any material traces of testimony of a deep past. The vision of this vision of the environment and the future of the environment. Science of self-intelligence, Prehistory defines trajectories that explain and justify us. His fascination is also based on the texture, the plasticity and the spirit of each haloed trace of a deep past. The clarity offered by this retrospective vision releases humanity from any biological attachment, any dependence on the environment: it requires us to see our total responsibility to the foundations of our destiny, past and future.
\end{abstract}

Keywords: Prehistory; Bipedalism; Feedback; Culture and Biology; Time and Space; Technique and Symbol; Demiurgic; Aesthetics and Function; Vital Transfers

\section{Introduction}

Founded on materiality, prehistory is primarily a contact, visual and tactile. Objects and traces give to see, think and smell, anything other than a written text or an oral narrative. Our senses first receive a stimulus that guides them to reflection, and rational justification comes only after this awakening to lucidity as well as to dreaming. Intellectual activity strained towards prehistory touches in the deepest the aspirations and the disturbing desires which agitate each of us on its origin, on its own nature, therefore on its destiny. Without knowing anything about why, we seek, and this activity holds us whole in concentration, well before a possible and authentic quest for a random historical reality, it will serve at best only pretext. Prehistory is based on emotion first, without which it does not exist. Like a music, like a poem, it is driven by an essential need for harmony, mystery and a vague notion of "truth", always dreamed but never real. You have to know how to admit it.

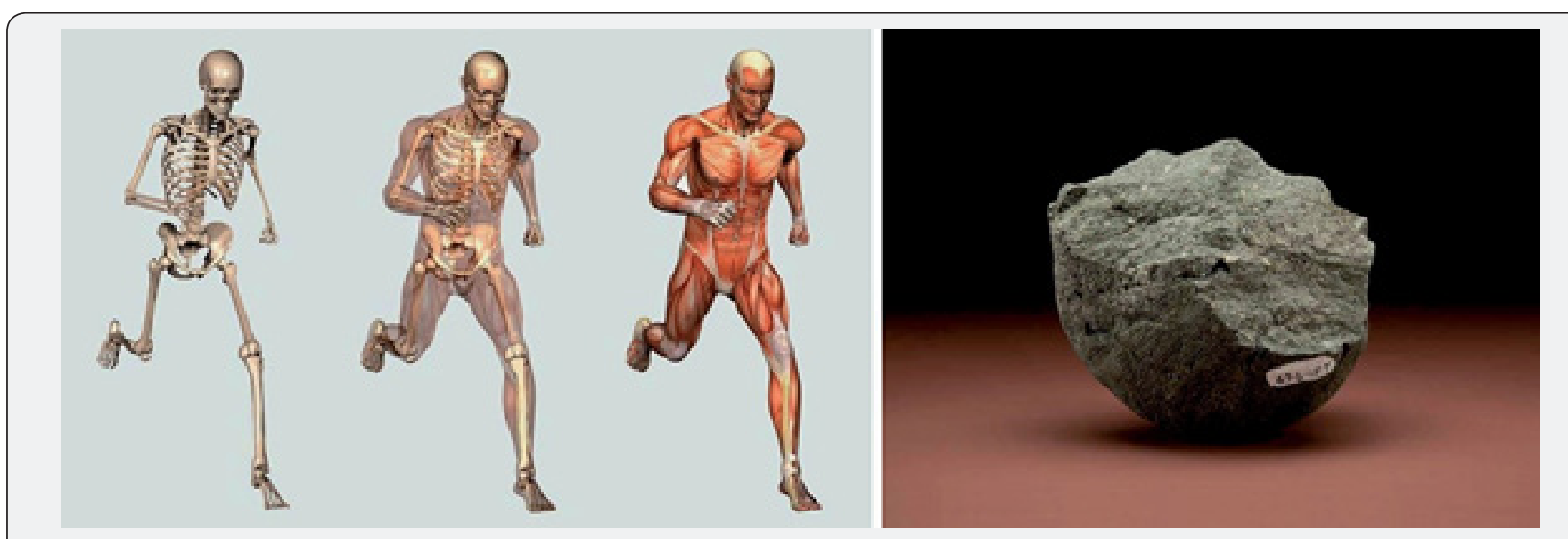

Figure 1: Bipedy was the first audacity, it was offset by the use of objects, external to the anatomy. According to Johanson \& Edgar, 1996. 


\section{The Biped}

Human evolution is based on a challenge to biology: this primate has chosen bipedalism, a taste for adventure and driven by daring. No other justification can explain because "everything was ready" before leaving the forest protection. Any unforeseen attempt would have been destroyed by the dangers present in open landscapes. Of all primates, only hominids have attempted and achieved this radical opposition to their natural destiny. The existential compensation for this anatomical deficiency has been produced by the use of "extra-somatic" tools, that is to say outside the body, and against the laws of the geographical environment.
These artifacts implied the reflections that gave birth to them and they are still legible on the stigmata of size, like fossilized linguistic sequences $[1,2]$. These objects extend the hands but also give meaning to the members who do not have them: they indicate the value of the gestures in their realizations and in their ability to transform the surrounding world. The true challenge of the spirit to the original condition engages all the human adventure, still active before our eyes. The first primate who tried it was endowed with an irreversible audacity: all his descendants no longer had this choice, they had to continue on this path incessantly (Figure 1).

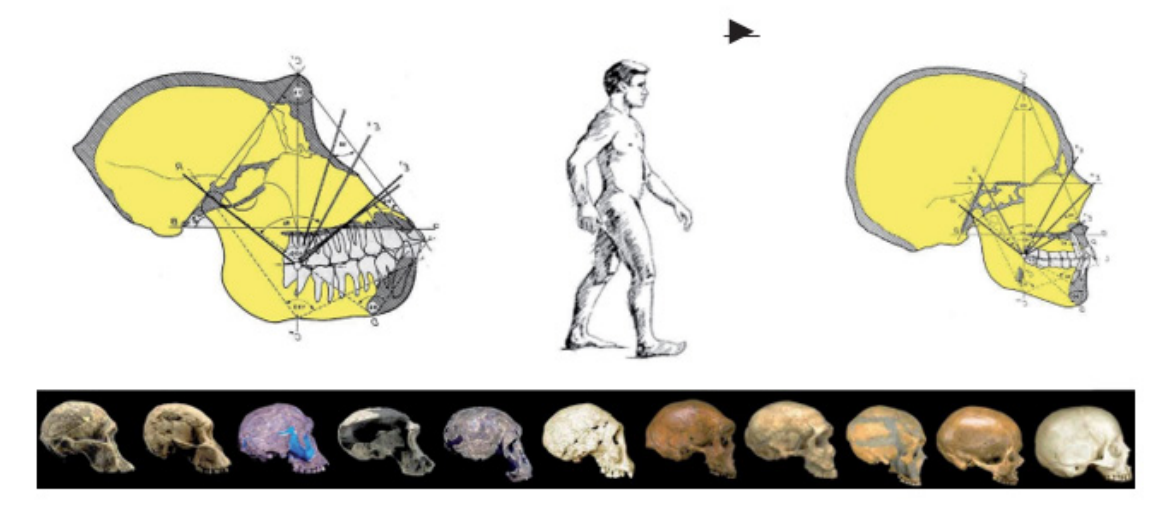

Figure 2: The rounding of the skull is only the retroactive effect of bipedalism. No region, no period is the point of origin of this totally universal mechanical process. According to Leroi-Gourhan, 1965.

\section{Feedback: Culture - Biology}

The "modernization" of the human skeleton has continued steadily under this guideline. The biped locomotion causes, without discontinuity, the straightening of the saddle and the liberation of the arms and therefore of the hands. The stabilization forces of the frame impose a perpetual rounding of the skull in order to balance it on the column. It is therefore not necessary to look for a point of origin of modern men: this process took place everywhere on earth and at every moment of our evolution. It is still in progress now, sometimes until the exaggeration of this mechanical effect, when the head possesses this tendency to fall backward. The modernization of our anatomy and our encephalon is a mere consequence of bipedalism [3]. It is a process linked to universal gravity, unrelated to cognition, nor to the size of the brain, nor to any of the higher-developed human "species" [4]. This mechanical process is simply growing according to the density of the demographic exchanges, which accentuate it as the rhythm imposed by time and by biological standardization. As in any open space, these trends become more standardized than in restricted environments. Symmetrically, the populations of archaic anatomy proceed with endogamous isolates in which the original features are not only preserved but especially accentuated such as caricatures, as much in the present islands as in the Pleistocene Europe, relatively protected from external contributions (Figure 2).

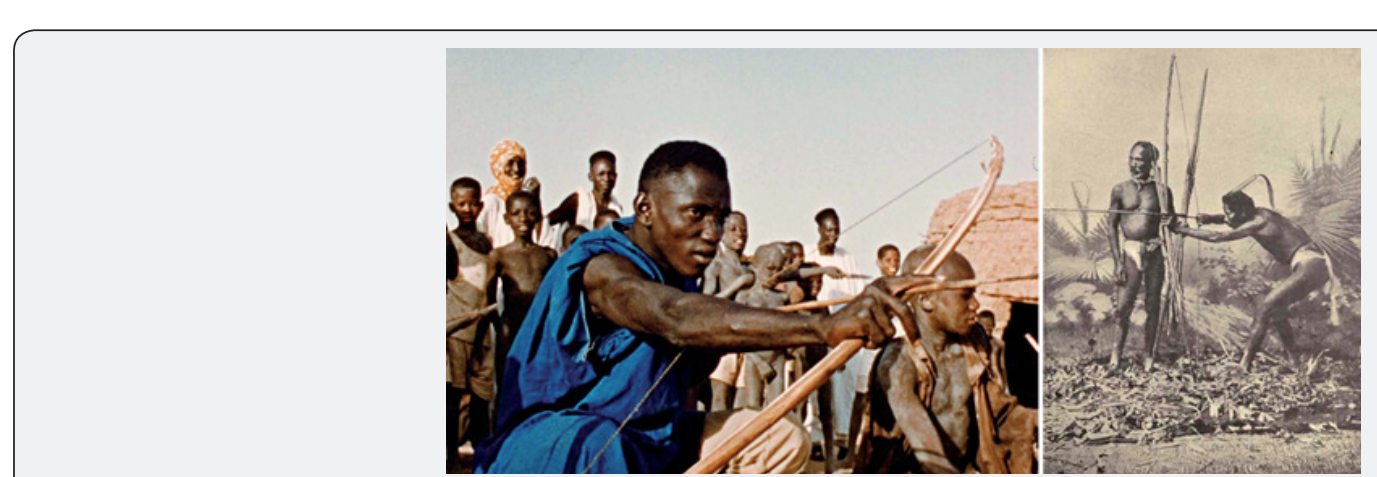

Figure 3: Ballistic processes based on relaxed tensions allow the conquest of distance and speed. They made man a competitor of the gods (African bow and arms of "negritos" in the Philippines). 


\section{Challenge Time and Space}

Since then, humanity has left forest protection thanks to its social rules as well as its ballistic conquests, over time and distance by the spinning jet or by loosening tight bows. The constraints then go from biology to culture because the new laws allow the liberation vis-à-vis nature but they impose customs, which form the new rules designed to ensure survival and mutual respect. As such, they tend to be sacralized as they enter the livelihoods, so give the keys to life itself [5]. It is in any case in this form that social rules are instituted and perpetuated. They now appear as the obligatory pathways of a life, an extension to those spontaneously rejected by natural laws. These codifications then pass through the language, the mythical narrative and the coded behaviors specific to each generation and to each of the social functions. Mankind is its own framework of rules that a new audacity will have to force, open to the perpetual title of freedom, become more conceptual than physical (Figure 3).

\section{The Technique and the Symbol}

The tool becomes the symbol of this opposition to nature, and its development will be like a sneaky undertaking of perpetual penetration of the spirit against the natural forces in order to impose the human will, always more subtle, more powerful. Mythologies have embodied this fundamental tendency in the space of the gods who forge peoples through the use of formidable weapons, such as the sword, the sword or the hammer. The tool, become weapon, turns then against the thought which makes it born. It becomes the trace of the subordination of men to each other, and the symbol of natural forces put to the profit of human existence. Any new form thus invented thus becomes an unheard-of creation opposed to natural biological productions. He embodies this bold thought, as much in its silhouette as in its suggested effectiveness, as a sign of its power. But any technical tendency, turned towards the demonstration of an efficient perfection, expresses above all the evolutionary force strained towards the equilibrium, the symmetry and the elegance. No technical constraint then acts in the sense imposed by physical laws, but it works precisely in the opposite direction, towards a game with their constraints [6].

As if the gesture tended to exceed the obligations imposed by the material, in order to be guided solely by the taste for pure, unprecedented, creative form. Any business towards a better efficiency on the real will inevitably lead to exactly reversed results: The mechanical functions are insured symbolically (cover, tool), but the evidence is of a harmonious order. he idea of this mechanical realization will then be relegated to the status of sym- bolic, at the source of purely aesthetic quests. A little like the ceremonial swords, never used in combat but always more expressive of the idea of the prestige conferred by the victory, as soon as they are more than a sign. The halberds of the Swiss guards can no longer be used for a long time, they are reduced to pure forms and belong to exclusively ostentatious functions. From the early Paleolithic period, this aesthetic tendency outweighs that of efficiency, and is at the source of our current typological confusions, since their use is extremely limited in space and time. in time: they have entered the fields of variation due to the traditional choices they embody (Figure 4).
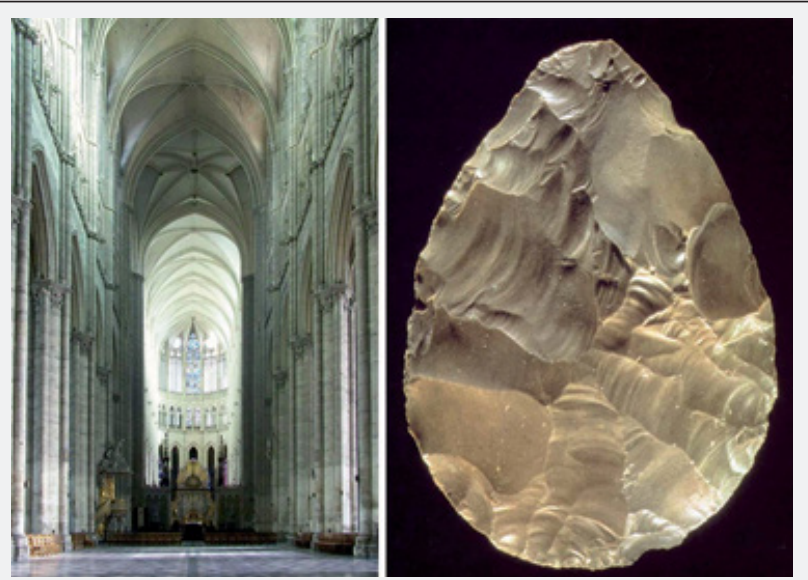

Figure 4: The aesthetic trend always prevails over efficiency alone (biface of Syria, according to Jean-Marie Le Tensorer 2009, nave of the cathedral of Amiens).

\section{The Demiurgic Action}

Among all these technical creations opposed to nature, is placed the control of fire, the most emblematic, because it offers immense possibilities to the grip of the conscience, really became "demiurgic". Heat in the cold, light in darkness, changes in matter are now at the service of the conscience and the human will. All this arsenal gives to the human mind, far more than these extraordinary achievements: it offers above all the conviction that all force can be understood and put at the service of the conscience in its practical activities. Man defies himself to the gods, this is where mythology comes to testify to this strictly metaphysical dimension: this is where Prometheus is condemned for stealing from the gods the keys of this power and giving them to men. Because, in the long term, metaphysical thought has nothing of the anecdote, it gives an explanation to long and lived situations at the origins of time, it justifies the current functioning and gives them a coherent explanation, and thus strengthens the customs, including 
those opposed to the world order. But fire is first and foremost a "home" where the family and the group come together and protect each other. It is around the fire that the rules are transmitted and that the teachings are lavished. This is also where spirits manifest themselves during ritual dances. This is where stories are recalled and where information is shared, projects are defined. Around the homes, society reinforces above all its cohesion and perpetuity. In this sense, fire is sacred, it is he who establishes the fundamental relationship between solitary spirits and hostile nature: the animals do not approach it and the climatic laws are reversed (Figure $5)$.
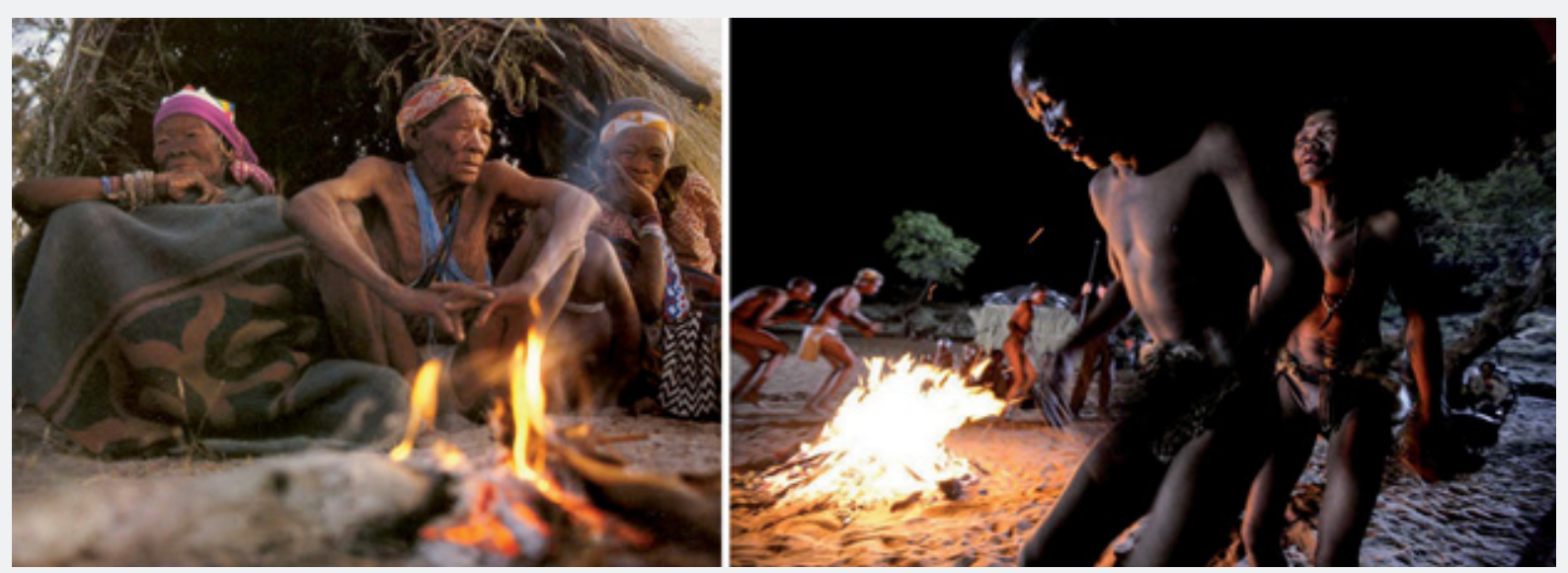

Figure 5: In addition, the fire becomes "home": it gathers, it protects, it is there where the education can be renewed, and the ceremonies accomplished collectively and ostensibly (Boschimans). According to Patou-Mathys, 2007.

The use of fire also transforms matter definitively, it transcends its natural characteristics, in the alchemical mode. Metals change their status, move from one element to another, offer unprecedented combinations, and profoundly modify societies that master the methods of treatment. At first ostentatious, the metal shines and combines in new materials with unknown mechanical criteria in their natural states. It therefore gives prestige to those who master it, even if it is not primarily in the specific field of technical efficiency. The symbol of this conquest imposes itself first and foremost on the practical reality. The decorative objects in bronze offer no advantage if not prestige, gold is malleable, and copper is altered. Yet on their very beginnings, the entire steel industry will shift human evolution from food production to exponential economic power and for no other purpose than to grow endlessly. The control of the techniques goes against the initial intentions, because they evolve in total autonomy by their only dynamics, such as a star moves in the infinite space, pushed on its initial impulse. All technological development goes in the same direction, launched by an ideology, it turns very quickly towards its designers and their interests, it obeys only its own principles [7].

Built against the laws of gravity, the monuments establish a relation between cosmos and the humanized earth, they perpetuate an intention, they give body to an ideal by offering it an ostentatious durability, imposed to all like a mountain or an element of order natural. They will remain more than the organic life, even more than the societies that wanted them, they are the guarantees for eternity, at least in their primary vocation. Everywhere, human societies have tried to capture time and landscape by petrifying a thought in a gigantic and firm sign. These spectacular marks have come down to us a few times since Neolithic times, but you only have to penetrate into a cave decorated deep to feel impregnated by the durability of the rock where these sets are placed. They impose themselves against time, via materially durable images, far beyond the mythological designers, long after the artists' disappearance, because the myths are designed to fight the ephemeral, and the momentum is there to convey this eternity to them, he bears the obvious testimony.

In a structurally analogous sliding process, the force of the animal, massive, formidable, dangerous, is transposed from a customary observation to a capture offered by its single image. The process is evident in recent civilizations that proceed by mythological illustration. But all the skulls and the massive remains of preserved animals form images just as much, from the earliest phases of humanity. Only their symbol is therefore important, in the analog form of a trophy, or in the realistic form of the bones themselves, even in the symbolic form of the word, of the dream, of the concept. This shift goes as far as affecting the recent religions, which see the reincarnation of divinities with animal forms, in systematic opposition with the ethereal and abstract gods imposed by the religions of the Book. Most of the time, abstraction has not suited minds teased by the need for a reality analogous to that experienced: all heresy has found its foundation in this attraction to the reality lived in everyday life.

The same phobia of the wild world no longer applies only to the image or idea but soon extends to animal behavior: its strength inevitably pushes the metaphysics to tame also its way of being, to impose our ways to make and live, to domesticate it. Only the high status of a wild animal justifies the enterprise of its mastery, it acts as a vector of the challenge, opposed to the man against all nature, against all that is not him. These savage forces first enter the myth where they remain untouchable, then they 


\section{Global Journal of Archaeology \& Anthropology}

arise in terms of behavior in ritual practices, finally they end up in the customs of breeding where they lose all sacrality. However, we do not domesticate all species, and we deliver only a fringe of freedom measured to "pets", which are precisely integrated socially because they embody this nostalgic savagery. Domestication is another step in the grip of symbolic thought on the world. It embodies the power over dangerous behavior, it makes it understandable because integrated social rules. Savagery is then lost in favor of profane activities, if not very significantly in "games", such as bullfighting or rodeos, where part of the risks is restored to natural vitality and where they still bear witness to these original challenges.

\section{Aesthetics and Function}

The best fight, however, is against his own death, and against the absurdity of time lived personally at the expense of ourselves. The burial comes to fight against this anxiety offering a substitute for the duration lost in reality but indicated by the subsequent adjustments to the common existence. The remains of the deceased give a destiny to the living: they are thus distinguished from animal remains, which follow another symbolic fate than ours. A whole range of signs designate them, including the colors of life (ochres), weapons, animal images, the functions of the living, offerings, as destined to an extension of existence. Often, skulls alone carry special treatments because this is where consciousness is held during life. They are isolated, separated, arranged, and modeled, like masks. The human image is then created in substitution for the living face. This analogical illusion can therefore persist indefinitely, preserving the physical features of life and the serene aspects that give it access to life. The history of the masks begins here, at the meeting between the individual and his role: the first is fleeting, the second persists and is placed indefinitely on other faces, including those of other deceased. The theatrical mask has no other function, no other origin, no other justification, including in Africa, Melanesia, or the Americas. It is always a question of offering a role fixed in advance to a contingency, which varies indefinitely, precisely in the successive phases of the states of the life of an individual. The mask freezes for a moment and imposes on him a definite role in advance and definitely. The first burials provoked this endless avalanche that still troubles us at every festival, at every carnivals and theaters on our streets, because a face exhibited in society is still a mask (Figure 6).

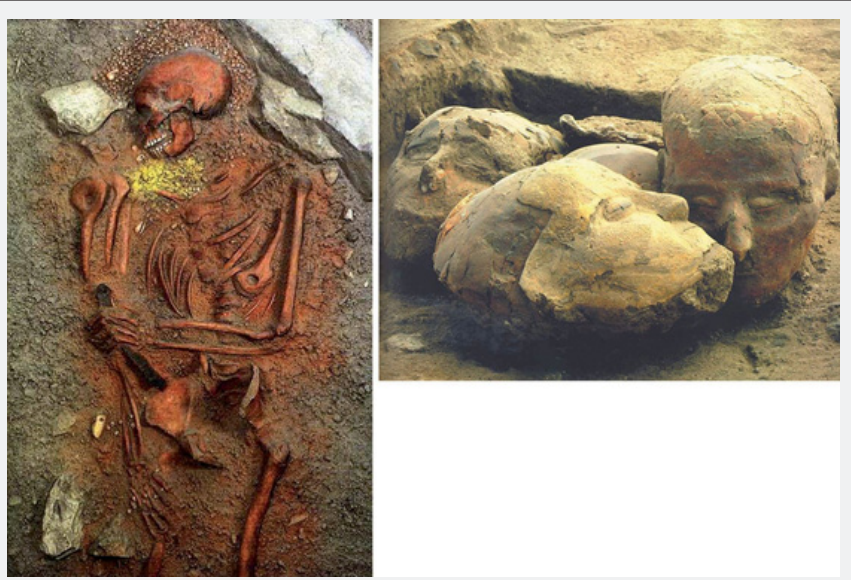

Figure 6: The fight against time takes its most lively form when it is conducted in relation to its own existence, in the funerary ritual and in the frozen expression of the masks (burial of the Cavillon, skulls on modelings of Aswad, Syria ).
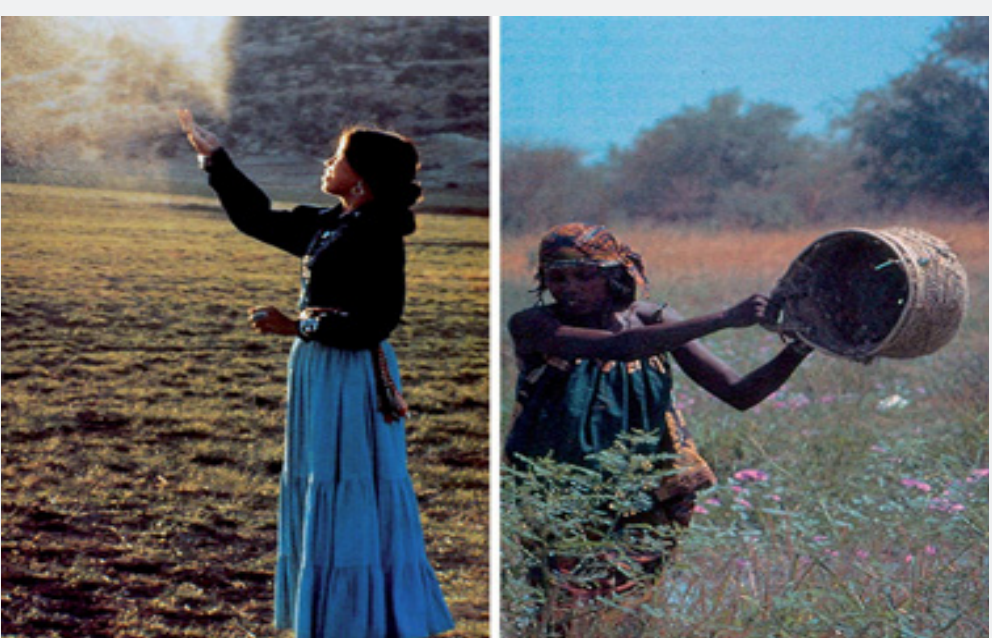

Figure 7: The food of the human group is ensured by the harvest of cereals (domestic or wild). 


\section{Vital Transfers}

The true conquest of existence is through food that transfers energy from one life to another, and everywhere this exchange is both plant-based and essentially According to $[8,9]$. a feminine affair, like the birth of human beings itself! This attraction towards the wild, fleshy and energetic seeds, is as much in the predatory people as the farmers. Wild cereals are harvested around the habitat by women and children, without prestige, but in an absolutely crucial form: the life itself of the group finds its ressources. Hunting is left to the challenges of structuring society, it has only symbolic value, spectacular as in the social classes that still practice them in our cultural circles. At both ends of the consumption, rituals of selection and harvests for revitalization, or restitutions part of the energy collected by an offering to the natural forces that made them grow (Figure 7).

The relation to vitality is a serious affair, which has nothing to do with the excessive festivities linked to the slaughter of game, everything is here se- kid and attentive, respectful of both the natural forces and the distribution within the social group. This sacredness can only be exercised by women in their generative, discrete and customary functions, as they are in procreation. This discrete gravity is opposed to the ostentation of hunting and its excesses, all the more expressive as they know they are useless, even marginal. Their exclusive symbolic motivation organizes the group and fights the beings of dangerous aspect, they are left to the young men to test their bravery. Once triggered, the domestication of cereals causes endless upheavals, demographics must increase to meet new and diverse tasks, nature is impoverished by reducing its diversity, and colonial displacements are required. The disease is implanted in all landscapes under control. The needs of new lands are unlimited, the expansion extends by killing especially the wild spirit of the men remained predators: they lose the values and the daring, like the current Aborigines. Less than a change in resources, the Neolithic is above all a loss of faith, a reduction of myths and a gradual transition to religions with gods and pantheons: the whole cosmos will be in the image of man and under his hold, even unconscious forces. Neolithic ideology is spreading much faster than the economy that follows it: it fascinates because it imposes its law on natural forces, as if it were a progress of consciousness on the unfolding of the world. No battle, no war can fight long against the flow of ideas, and we are still there: ideological illusions touch far beyond borders, and they kill much more surely than weapons.

Population concentrations inevitably follow. They require writing that inhibits the imagination and the oral narrative. The rules are inscribed, they perpetuate laws to which one can return, to refer. It is no longer the sky taken to witnesses, it is the law that imposes itself via the text written, codified, fixed. It becomes syn- onymous with order, reason, good and justice. Relationships no longer undergo initiative, compassion, freedom, except if they are referential to codes, outdated in existence, but consensual. However, any law calls for revolt, just as natural constraints have led to the audacity of bipedalism, or the shaping of tools, the control of fire. The human mind is never satisfied with constraints: it is the implacable law imposed by human prehistory, perpetually recommenced: adventure gives substance to existence, its value must be constantly renewed, maintained, defended. More than ever, contacts made so tightly across today's societies limit initiatives and their spaces. Prehistory puts us in front of our responsibilities. The dogmatism of the cardinals has been confronted with the strength of the mystics, for humanity is always alternating rule and daring.

Henceforth, our lucidity prevents us from having access to the satisfaction of letting mythologies or "natural laws" explain all new situations that are crossed over time. And, through consciousness, we escaped biological determinism. But the exacerbated exercise of this consciousness forces us today to assume full responsibility for our choices. All human prehistory has shown that only our decisions have guided our evolution. What made man is neither environmental constraints nor his own biological components, but always his own decisions, based on his dreams and systematically opposed precisely to laws, natural or human. This lesson given by prehistory requires us to know where our homework is and tells us that only our choices have always "determined" us, and that we have become totally responsible for what we are going to become.

\section{References}

1. Donald J, Black (1996) From Lucy to Language. Orion House, New York, USA.

2. Patou Mathis M (2003) Behaviors of Middle and Upper Paleolithic men in Europe: territories and environments. Proceedings of the G.D.R. 1945 CNRS, Paris, 8-10 ERAUL 111, Liège, Belgium, pp. 213-229.

3. Ki Zerbo J (1980) General History of Africa. I. Methodology and African prehistory. Unesco, Paris.

4. The Tensorer JM (2009) The search for symmetry. In: Azoulay E, Picq P, Vigarello G, Marc Nouschi M, Gaillard Fr (Eds.), 100,000 years of beauty, Gallimard, Hors-série Beaux Livres, Paris.

5. Otte M (2018) The audacity of Sapiens. How humanity is constituted. Odile Jacob, Paris.

6. Patou Mathis M (2007) A death announced. Meet the Bushmen, the last hunter-gatherers of the Kalahari. Perrin, Paris.

7. Reed Ch (1977) Origins of agriculture. International Congress of Anthropological and Ethnological Sciences (9 $9^{\text {th: }}$ 1973: Chicago, Ill.), Sheep, The Hague, Netherlands.

8. Henry GD (2003) Evolution of Funerary Practices in Upper Palaeolithic Italy. In: Vialou D, Renault-Miskovsky.

9. May F (1986) Prehistoric burials. Critical study. Edition of the CNRS, Paris. 
This work is licensed under Creative Commons Attribution 4.0 License DOI: 10.19080/GJAA.2019.10.555794
Your next submission with Juniper Publishers will reach you the below assets

- Quality Editorial service

- Swift Peer Review

- Reprints availability

- E-prints Service

- Manuscript Podcast for convenient understanding

- Global attainment for your research

- Manuscript accessibility in different formats ( Pdf, E-pub, Full Text, Audio)

- Unceasing customer service

Track the below URL for one-step submission https://juniperpublishers.com/online-submission.php 